\title{
The Effectiveness of Virtual Reality in Managing Acute Pain and Anxiety for Medical Inpatients: Systematic Review
}

Vinayak Smith ${ }^{1,2^{*}}$, MBBS, DPhil; Ritesh Rikain Warty ${ }^{1,2^{*}}$, BEng; Joel Arun Sursas ${ }^{2}$, MBBS; Olivia Payne ${ }^{1}$, BBSc; Amrish Nair ${ }^{2}$, MEng; Sathya Krishnan ${ }^{3}$, MBBS; Fabricio da Silva Costa ${ }^{1,4}$, DPhil; Euan Morrison Wallace ${ }^{1}$, MD; Beverley Vollenhoven ${ }^{1}$, MBBS, DPhil

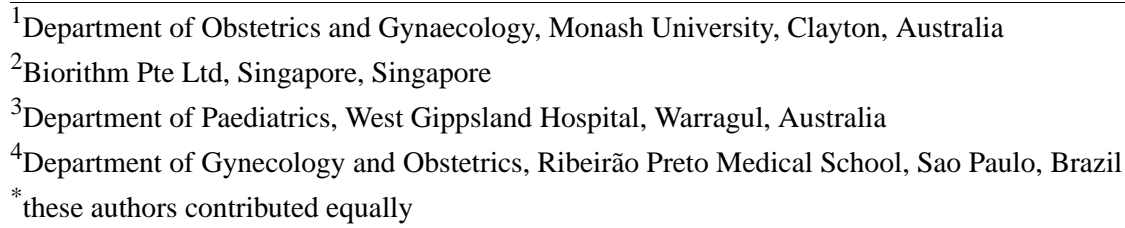

\section{Corresponding Author:}

Vinayak Smith, MBBS, DPhil

Department of Obstetrics and Gynaecology

Monash University

246 Clayton Road

Clayton

Australia

Phone: 61431330754

Email: vinayak.smith@monash.edu

\section{Abstract}

Background: Virtual reality is increasingly being utilized by clinicians to facilitate analgesia and anxiolysis within an inpatient setting. There is however, a lack of a clinically relevant review to guide its use for this purpose.

Objective: To systematically review the current evidence for the efficacy of virtual reality as an analgesic in the management of acute pain and anxiolysis in an inpatient setting.

Methods: A comprehensive search was conducted up to and including January 2019 on PubMed, Ovid Medline, EMBASE, and Cochrane Database of Systematic reviews according to PRISMA (Preferred Reporting Items for Systematic Reviews and Meta-Analyses) guidelines. Search terms included virtual reality, vr, and pain. Primary articles with a focus on acute pain in the clinical setting were considered for the review. Primary outcome measures included degree of analgesia afforded by virtual reality therapy, degree of anxiolysis afforded by virtual reality therapy, effect of virtual reality on physiological parameters, side effects precipitated by virtual reality, virtual reality content type, and type of equipment utilized.

Results: Eighteen studies were deemed eligible for inclusion in this systematic review; 67\% (12/18) of studies demonstrated significant reductions in pain with the utilization of virtual reality; $44 \%(8 / 18)$ of studies assessed the effects of virtual reality on procedural anxiety, with 50\% (4/8) of these demonstrating significant reductions; 28\% (5/18) of studies screened for side effects with incidence rates of $0.5 \%$ to $8 \% ; 39 \%$ (7/18) of studies evaluated the effects of virtual reality on autonomic arousal as a biomarker of pain, with $29 \%$ (2/7) demonstrating significant changes; 100\% (18/18) of studies utilized a head mounted display to deliver virtual reality therapy, with $50 \%$ being in active form (participants interacting with the environment) and $50 \%$ being in passive form (participants observing the content only).

Conclusions: Available evidence suggests that virtual reality therapy can be applied to facilitate analgesia for acute pain in a variety of inpatient settings. Its effects, however, are likely to vary by patient population and indication. This highlights the need for individualized pilot testing of virtual reality therapy's effects for each specific clinical use case rather than generalizing its use for the broad indication of facilitating analgesia. In addition, virtual reality therapy has the added potential of concurrently providing procedural anxiolysis, thereby improving patient experience and cooperation, while being associated with a low incidence of side effects (nausea, vomiting, eye strain, and dizziness). Furthermore, findings indicated a head mounted display should be utilized to deliver virtual reality therapy in a clinical setting with a slight preference for active over passive virtual reality for analgesia. There, however, appears to be insufficient evidence to substantiate the effect of virtual reality on autonomic arousal, and this should be considered at best to be for investigational uses, at present. 
(J Med Internet Res 2020;22(11):e17980) doi: 10.2196/17980

\section{KEYWORDS}

virtual reality; VR; pain management; anxiety; procedural pain; wound management; acute pain; analgesia; pain

\section{Introduction}

\section{Background}

The International Association for the Study of Pain defines pain as an "unpleasant sensory and emotional experience associated with actual or potential tissue damage [1]." As a disease, pain carries a huge global burden with a prevalence of $20 \%$ and incidence of $10 \%$. It negatively affects one's psychological and social functioning, thereby impinging on quality of life too. Its tangible costs cannot be understated as well, with research demonstrating a loss in productivity owing to absenteeism and diminished job performance as a result [2-7].

Acute pain is a commonly encountered clinical entity in up to $84 \%$ of patients presenting to medical services [8]. Acute pain is sudden in its onset and is typically expected to last for a short time ( $\leq 6$ weeks). Usually, it can be attributed to a specific event or illness, but at times, it may be iatrogenic [9].

Either pharmacologic (analgesics) and nonpharmacologic (interventions) can be used for addressing acute pain. Within analgesics, opioids are often prescribed [10]. This strategy, although clinically effective, has several disadvantages. Opioids are notorious for their deleterious side effects, including tolerance, dependence, and hyperalgesia [11]. Additionally, some analgesics also require invasive procedures to be administered, such as with intrathecal infusions, which carry their own set of clinical risks and side effects. Similarly, concerns have been raised toward nonpharmacologic approaches (ie, transcutaneous electrical nerve stimulation, hot or cold compress), with regard to their efficacy and appropriateness in the setting of acute pain $[10,11]$.

In light of these findings, as well as the recent recommendations from the American Pain Society and the American Society of Anaesthesiologists, there remains an urgent need to characterize and identify alternative modalities for acute pain relief. In particular, there is a need for these therapies to be clinical efficacious, be minimally invasive, and potentiate low levels or negligible side effects [12]

Virtual reality is a burgeoning technology which is in its infancy of uptake for clinical utilization. As a technology, virtual reality allows for users to be immersed in a virtual environment through multisensorial stimulation $[13,14]$.

Over the last decade, increasing attention and research has been directed toward assessing the utility of virtual reality in managing acute pain. While there is presently no clear explanation of virtual reality's mechanism of pain relief available, several theories which span the realms of biology and psychology exist to elucidate its efficacy $[15,16]$. To date, it is also worthy of mention that virtual reality therapy has been successfully used as an analgesic in several acute clinical contexts, ranging from pediatric phlebotomy to dressing changes for burns and postcardiac surgery [17-19].

\section{Objectives}

The main motivation for our group in undertaking this systematic review was to provide a comprehensive literature review to inform the clinical utilization and testing of virtual reality therapy.

Primarily, this encompassed understanding the applicability of virtual reality in facilitating analgesia during acute pain for inpatient populations. This also included an understanding of virtual reality therapy headsets, content being used for the indication, and the effects of virtual reality on anxiolysis, since it has been implicated in facilitating this effect, which in turn, modulates the patient's perception of pain [20,21]. Furthermore, we aimed to delineate the effect of virtual reality on physiological parameters (autonomic arousal); literature has suggested that these are biomarkers of pain, and thus, are theoretically correlated with pain responses [22]. Last, given the impact that it would have on patient safety and clinical uptake, we wanted to understand virtual reality therapy's side effect profile.

Prior to undertaking this review, there was a gap in the literature on virtual reality therapy, in the setting of facilitating inpatient acute analgesia, which was of practical relevance to the clinician. This, in our opinion, appeared to be a barrier of clinical uptake which we aimed to address through this initiative by providing a holistic overview.

\section{Methods}

\section{Data Sources}

The following review was conducted in line with PRISMA (Preferred Reporting Items for Systematic Reviews and Meta-Analyses) guidelines. The search was undertaken on PubMed, Ovid Medline, EMBASE, and the Cochrane Database of Systematic Reviews up to and including May 2018 by VS, JS, AN, and SK and repeated up to and including January 2019 by VS, RRW, OP, and JS. The search was carried out without any limit of the years, and articles were restricted to those in English. The databases were searched independently by the aforementioned authors. Once shortlisted, full texts were ordered and read. The bibliographies of articles selected for the review were also screened for suitable additional articles to be included in this review. Inclusion in the review was selected by consensus between the screening authors.

Inclusion criteria were primary studies utilizing virtual reality in the management of acute pain in a clinical setting. Interventions were considered to be virtual reality only if they employed an audio or visual multimedia environment with which the patients could view or interact (ie, games and videos). Acute pain was defined as pain that was less than 6 weeks in duration and associated with an acute condition or medical procedure. The context was selected to make the findings relevant to the inpatient treatment of patients for clinicians. 
Studies with both adult and pediatric populations were suitable for inclusion in the review.

Articles that were reviews, case series, or case reports were excluded from this review. Experimental studies of a nonclinical nature (eg, pain induced via cold-pressor test) were excluded in a bid to focus on clinically relevant pain reduction which could be easily extrapolated to clinical practice.

\section{Search Strategy}

Search terms used across all databases were (virtual reality $\mathrm{OR}$ $v r$ ) AND pain. Studies were then filtered manually as per the inclusion criteria for acute pain associated with acute conditions or procedures.

\section{Data Collection Process}

Data were extracted manually for analysis by VS, SK, and JA in tabular form. Due to the heterogeneity of the studied populations, variations in technologies utilized, and heterogeneity in the endpoints of the studies; pooling of data for meta-analysis was not considered appropriate. In addition, meta-analysis of data from rapidly evolving medical technologies of various generations was deemed inappropriate [23]. This is due to the lack of similarity between technologies, the impact of incremental innovation between generations of the same technology and the presence of operator dependence (from a clinician and patient perspective) on its performance [23]. As such, a narrative approach was followed for this review.

\section{Data Items}

Data items of interest for the studies included: year of study, study design, sample size, clinical setting, population, nature of the intervention, control or comparison, virtual reality content type, main outcomes measures, outcome measurement tools, and technical specifications of virtual reality devices employed. Technical specifications of virtual reality devices included type of head mounted display, display utilized, weight of device, field of view, computer, video card, controller, virtual reality content type, and virtual reality content used.

\section{Assessment of Bias}

The risk of bias was assessed by VS and RRW using the modified Downs and Black List [24] and scored on a scale of $1-10$ as illustrated in Table 1.

Table 1. Summary of bias assessment results using modified Downs and Black checklist.

\begin{tabular}{|c|c|}
\hline Study & Score (out of 10 ) \\
\hline Chad et al [25] & 9 \\
\hline Chan et al [26] & 6 \\
\hline Chau et al [27] & 8 \\
\hline Frey et al [28] & 9 \\
\hline Gerceker et al [29] & 10 \\
\hline Gershon et al [30] & 8 \\
\hline Glennon et al [31] & 9 \\
\hline Gold et al [32] & 9 \\
\hline Hoffman et al [18] & 8 \\
\hline McSherry et al [33] & 7 \\
\hline Mosso-Vasquez et al [17] & 8 \\
\hline Mosso-Vasquez et al [34] & 7 \\
\hline Nilsson et al [19] & 9 \\
\hline Piskorz et al [35] & 8 \\
\hline Shoorab et al [36] & 9 \\
\hline Tashjian et al [37] & 9 \\
\hline Walker et al [38] & 8 \\
\hline Yun Hua et al [39] & 9 \\
\hline
\end{tabular}

\section{Summary Measures and Synthesis of Results}

The primary measures of interest were degree of analgesia afforded by virtual reality therapy, degree of anxiolysis afforded by virtual reality therapy, effect of virtual reality on physiological parameters, side effects precipitated by virtual reality, measures of pain assessment, virtual reality content type, and types of equipment utilized.

\section{Patient and Public Involvement}

No patients were involved in the design, recruitment, or conduct of the study. There was no intention a priori that the results of this review would be disseminated to patients included in the trials of the review. 


\section{Results}

\section{Study Characteristics}

\section{General Description of Studies}

A total of 18 studies were deemed suitable for inclusion in this review [17-19,25-39]. The article selection process is outlined in Figure 1.

Figure 1. PRISMA flow diagram.

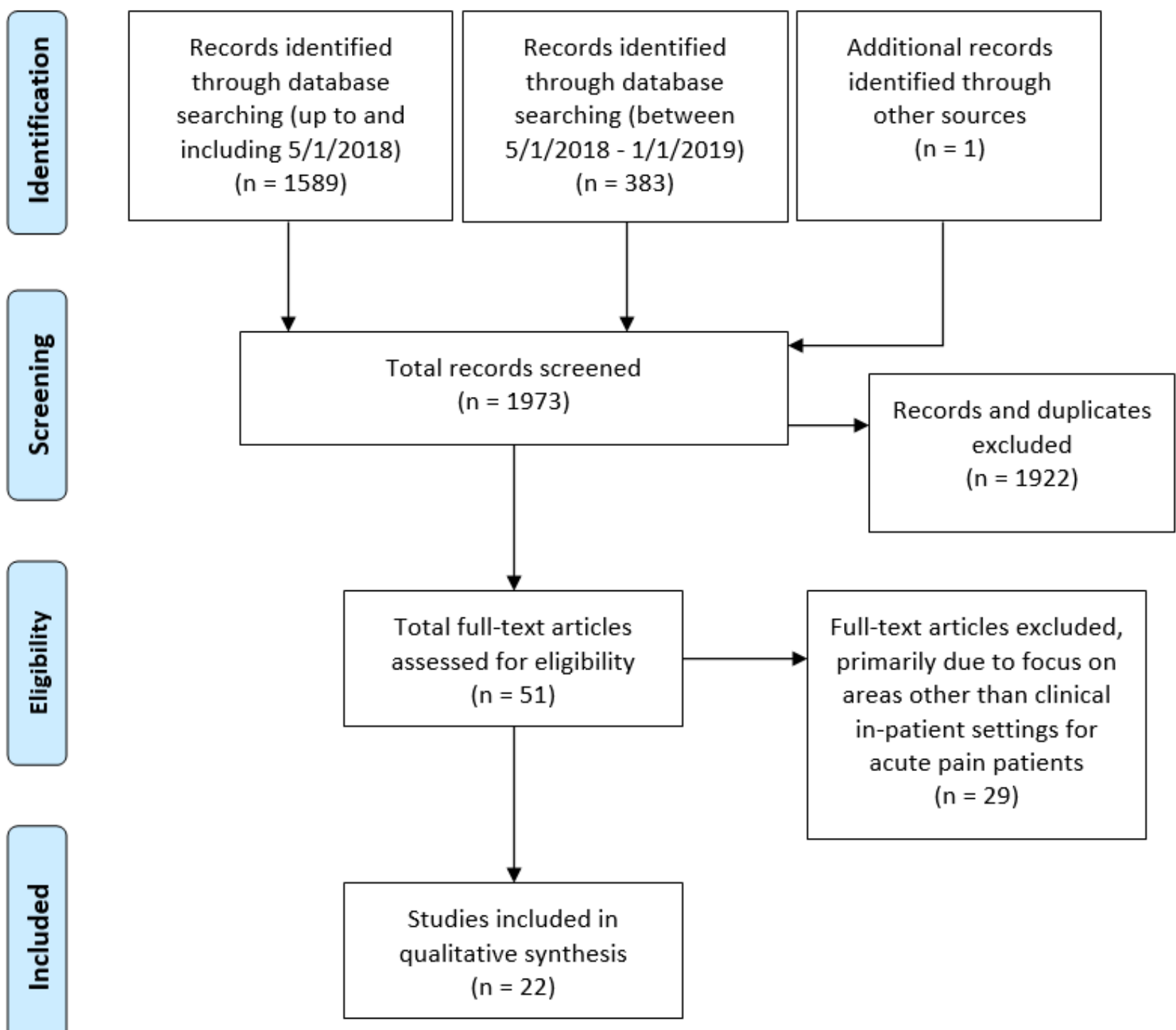

\section{Indications for Virtual Reality Utilization}

Of the 18, 22\% (4 studies) measured pain reduction in patients undergoing dressing changes or hydrotherapy for burns or wounds [18,26,33,39]; 39\% (7 studies) looked at patients undergoing venipuncture, port access, or injections [19,25,27,29,30,32,35]; 39\% (7 studies) measured pain outcomes in patients undergoing various invasive procedures ( 5 studies) $[17,31,34,36,38]$ or other miscellaneous acute conditions $(2$ studies) [28,37].
The descriptive data collated from the eligible studies are reported in Table S1 (Multimedia Appendix 1). All 18 studies were conducted and published between 2004 and 2018: 50\% $(9 / 18)$ of studies were specifically focused on the pediatric population; $72 \%$ (13/18) of studies compared virtual reality against standard analgesia as the comparator/control group [18,19,26,29-36,38,39]; 28\% (5/18) of studies compared virtual reality to no analgesia $[17,25,27,28,37]$. Overall, only 1 study of $18(6 \%)$ received a bias assessment score less than 7 out of 10.

\section{excluded \\ $n=1922$}

\section{Technical Specifications of Virtual Reality Systems Utilized}

Table S2 (Multimedia Appendix 2) summarizes data on the technical specifications of devices.

All studies (18/18, 100\%) utilized head mounted displays which allowed for monitoring of head orientation. Half $(9 / 18,50 \%)$ used active virtual reality content in the form of games $[18,19,26,30,32,33,35,38,39]$ as the primary content, and the remaining $50 \%$ of the studies $(9 / 18)$ employed passive virtual reality content in the form of virtual environments and movies. 
One-third $(6 / 18,33 \%)$ applied a virtual environment $[17,25,28,31,34,37]$, and $17 \%(3 / 18)$ displayed a cartoon or movie $[27,29,36]$.

\section{Summary of Measures and Synthesis of Results}

\section{Effect on Analgesia}

Overall, $67 \%(12 / 18)$ of studies in this review demonstrated a statistically significant reduction in pain during virtual reality utilization; $83 \%(10 / 12)$ of these demonstrated a statistically significant reduction in pain using a between-group design [18,26,28-30,32,35-37,39]. Within these 10 studies, only 1 received a score less than 7 on the bias assessment checklist. The remaining $17 \%$ (2/12) of studies demonstrated statistically significant reductions in perceived pain utilizing a within-group design $[25,34]$. Across studies, the clinical endpoint of pain was measured through a variety of pain measurement tools. These results and tools are described in Table 2. 
Table 2. Summary of studies for utility of virtual reality in acute pain.

\begin{tabular}{|c|c|c|c|c|}
\hline Study & Intervention & Standard care; control & Measurement tools & Results \\
\hline \multirow[t]{3}{*}{ Chad et al [25] } & \multirow[t]{3}{*}{$\mathrm{VR}^{\mathrm{a}}$} & \multirow[t]{3}{*}{$\mathrm{N} / \mathrm{A}^{\mathrm{b}}$} & \multirow[t]{3}{*}{ FACES $^{c}$ (scale of 0-5) } & $\begin{array}{l}\text { Descriptive evidence of significantly reduced pain as } \\
\text { reported by parents: } 83 \% \text { reduction }(P=.02) \text { in pain } \\
\text { noted pre-VR (mean } 3.34 \text {, SD } 1.30) \text { and post-VR (mean } \\
0.76 \text {, SD } 1.06) \text {. }\end{array}$ \\
\hline & & & & $\begin{array}{l}\text { Insignificant reduction in pain reported by children: } \\
77 \% \text { reduction in pain noted with VR use (mean differ- } \\
\text { ence }-2.5 ; P=.52 \text { ). }\end{array}$ \\
\hline & & & & $\begin{array}{l}\text { No information on pain score from children and vari- } \\
\text { ance. }\end{array}$ \\
\hline Chan et al [26] & VR & Routine analgesia & FACES (scale of 0-100) & $\begin{array}{l}\text { Significant differences }(P<.05) \text { of pain intensity found } \\
\text { between VR group and non-VR group with ANOVA }{ }^{\mathrm{d}} \text { : } \\
\text { pain during procedure (VR: mean } 38.13, \text { SD } 12.02 \text {; } \\
\text { control: mean } 53.75, \text { SD } 11.80) \text { and pain after procedure } \\
\text { (VR: mean } 8.75, \text { SD } 2.95 \text {; control: mean } 18.75 \text {, SD } \\
\text { 9.53). }\end{array}$ \\
\hline \multirow[t]{3}{*}{ Chau et al [27] } & \multirow[t]{3}{*}{ VR } & \multirow[t]{3}{*}{ N/A } & \multirow[t]{3}{*}{ FLACC $^{\mathrm{e}}$ (scale of 0-10) } & $\begin{array}{l}\text { FLACC scores with VR use: median } 2.5 \text { (1-5.5); range } \\
(1-8) \text {. }\end{array}$ \\
\hline & & & & $\begin{array}{l}64.3 \%(9 / 14) \text { of caregivers felt that the VR experience } \\
\text { was positive and wanted to use it again. No between } \\
\text { group differences explored for the following study. }\end{array}$ \\
\hline & & & & $\begin{array}{l}\text { Descriptive evidence of reduced pain as reported by } \\
\text { parents. }\end{array}$ \\
\hline
\end{tabular}

Frey et al [28]

Gerceker et al [29] VR

Gershon et al [30] VR with topical anesthetic
Unmedicated labor

External cold and vibration (buzzy); analgesia alone

Video game with topical anesthetic; topical anesthetic

Analgesia alone

Glennon et al [31] VR

VR and analgesia

Analgesia alone
Gold et al [32]

Hoffman et al [18] VR and analgesia Analgesia alone GRS $^{1}$

$\operatorname{VNS}^{\mathrm{f}}$ (scale of $\left.0-10\right)$
Wong Baker FACES (scale of $0-10$ )

VAS $^{\mathrm{g}}$ (scale of 0-100); $\mathrm{CHEO}^{\mathrm{h}}$ pain scale
Worst pain intensity was significantly lower in VR vs control $(-1.5(95 \% \mathrm{CI},-0.8$ to -2.2$)$.

Significant differences in difference of pain intensity found between VR group and non-VR group with ANOVA.

There was a statistically significant difference observed in pain scores between the VR group and control as reported by the patients (VR: mean 1.5, SD 0.2; control: mean 5.1 , SD $0.4 ; P<.01$ ) and parents (VR: mean 1.5 , SD 0.2; control: mean 4.7, SD $0.4 ; P<.01)$.

There was a significant reduction in pain in the VR and non-VR distraction group as observed by nurses $(P<.05)$ based on MANOVA ${ }^{\mathrm{i}}$. No summary measures were provided in the paper.

From the CHEO pain scale, the VR group had significantly fewer behavioral markers in comparison to those of the controls for pain $(P<.05)$. No summary measures were provided in the paper.

No summary statistics on pain score from children and variance.

$\operatorname{NPS}^{\mathrm{j}}$ (scale of $\left.0-10\right)$

Participants in the VR group (mean 3.9, SD 2.3)did not experience a statistically significant decrease $(P<.05)$ in pain and anxiety in comparison to controls (mean 4 , SD 2.7).

Not powered adequately. Recruited individuals with prior exposure to bone marrow biopsy which may have skewed the reporting of pain.

VAS (scale of 0-10); $\quad$ Significantly less pain $(P<.05)$ was reported by the VR $\mathrm{CAS}^{\mathrm{k}}$; FACES group (mean 1.31, SD 1.59) compared to that reported by the control group (mean 1.93, SD 2.22).
Statistically significant reduction $(P<.01)$ in pain observed in VR (mean 7.6, SD 1.9) vs control (mean 5.1, SD 2.6). 


\begin{tabular}{|c|c|c|c|c|}
\hline Study & Intervention & Standard care; control & Measurement tools & Results \\
\hline $\begin{array}{l}\text { McSherry et al } \\
\text { [33] }\end{array}$ & VR and analgesia & Analgesia alone & $\begin{array}{l}\text { VNS; opioid administra- } \\
\text { tion }\end{array}$ & $\begin{array}{l}\text { Total opioid administration during VR therapy was } \\
\text { significantly less than that when no VR was used (VR: } \\
91.7 \text { SD } 10.1 \text {; no VR: } 103.1 \text { SD } 16.1 \mu \mathrm{g} / \mathrm{kg} ; P<.05) \text {. }\end{array}$ \\
\hline
\end{tabular}
Overall, $39 \%$ less opioids were used with VR therapy.

Pain scores (post procedure - pre procedure) were not significantly $(P>.05)$ reduced in VR group (mean difference -1.2 , SD 2.9) vs control (mean difference - $0.3, \mathrm{SD}$ 1.7).

Mosso-Vasquez et VR and analgesia N/A al [17]

Mosso-Vasquez et VR and analgesia al [34]

\section{Nilsson et al [19] VR and analgesia}

Piskorz et al [35] VR and analgesia

Shoorab et al [36] VR and analgesia

Tashjian et al [37] VR

Walker et al [38]

$\mathrm{VR}$
Analgesia alone

VAS

Analgesia alone

VNS

Mobile VR and analge- VAS sia

Analgesia alone

CAS; FAS ${ }^{\text {n }}$ FLACC

Nature video

VNS

VAS
$88 \%$ of patients reported a reduction in pain after VR therapy. Mean change in the Likert pain scale was 3.75. No descriptive statistics were provided.

Change in pain scores (post procedure - pre procedure) was substantially correlated with change in respiratory rate $\left(R^{2}=0.26\right)$. It was, however, minimally correlated with heart rate $\left(R^{2}=0.05\right)$, mean arterial pressure $\left(R^{2}=0.09\right)$, and $\mathrm{SpO}_{2}{ }^{\mathrm{m}}\left(R^{2}=0.00\right)$.

Overall, both head mounted display (presurgery: 6.06; postsurgery: 1.73 ) and mobile groups (presurgery 3.78 ; postsurgery 0.64$)$ showed significant reductions $(P<.01)$ in pain with VR.

Head mounted display VR group experienced a significantly greater pain reduction from intra to postoperative states in comparison to the mobile VR group $(-1.5 \mathrm{vs}$ $-0.07 ; P=.02)$.

No significant difference in CAS, FAS, and FLACC scores between VR and non-VR groups $(P>.05)$. No descriptive statistics were provided.

The VR group (mean 15.16, SD 20.51) reported significantly lower $(P<.02)$ pain intensity compared to that of the control group (37.05 SD 30.66). Pain intensity was $59 \%$ lower in the VR group than in the control with a large effect size (Cohen $d=0.86$ ).

Statistically significant reduction in the pain scores were observed during episiotomy repair in the VR group using ANOVA (VR effect: $f=88.6, d f=1, P<.01$ ).

VR group had lower pain scores during several phases of the procedure in comparison to those of the non-VR group $(P<.0001)$ : during the repair of the hymen (VR: mean 9.0, SD 12.6; non-VR: mean 23.6, SD 19.8), skin (VR: mean 16.7, SD 16.5; non-VR: mean 39.3, SD 22.5), and after the repair (VR: mean 6.0, SD 12.8; nonVR: mean 25.2, SD 14).

Pain reduction in the VR group (preintervention: mean 5.4, SD 2.6; postintervention: mean 4.1, SD 2.7) was greater (percentage reduction: $24 \%$ vs $12.2 \%, P<.01$ ) than that in the control group within subjects (preintervention: mean 5.4, SD 2.6; postintervention: mean 4.8 SD 2.7).

Higher number of responders in VR in comparison to control ( $\geq 0.5 \mathrm{SD}$ drop in pain) (65\% vs $40 \%, P<.01)$.

No significant difference in pain scores $(P>.05)$ between VR group and control—average pain (VR: $44 \mathrm{~mm}$; control: $43 \mathrm{~mm}$ ) and worst pain (VR: $66 \mathrm{~mm}$; control: $59 \mathrm{~mm}$ )—during the procedure. 


\begin{tabular}{lllll}
\hline Study & Intervention & Standard care; control & Measurement tools & Results \\
\hline Yun Hua et al [39] & VR and analgesia & Analgesia alone & FACES;VAS; FLACC & $\begin{array}{l}\text { Significantly less pain reported in the VR group com- } \\
\text { pared to the control group before, during and after the } \\
\text { dressing change }(P<.05) \text {. Also, significantly lower } \\
\text { scores during dressing change in VR vs control }(P<.05) \text { : }\end{array}$ \\
& & & $\begin{array}{l}\text { FACES-VR: mean 2.42, SD 1.85; control: mean 4.19, } \\
\text { SD 2.12) }\end{array}$ \\
& & & VAS-VR: mean 4.35, SD 2.64; control: mean 6.25, \\
& & SD 2.84) \\
& & FLACC-VR: mean 4.18, SD 2.97; control: 7.36, SD \\
& & $3.47)$. \\
\hline
\end{tabular}

${ }^{\mathrm{a}} \mathrm{VR}$ : virtual reality.

${ }^{b}$ N/A: Not applicable.

${ }^{c}$ FACES: facial analysis scale (such as the Wong-Baker Faces Scale).

${ }^{\mathrm{d}}$ ANOVA: analysis of variance.

${ }^{\mathrm{e}}$ FLACC: Face, Legs, Activity, Cry, Consolability.

${ }^{f}$ VNS: verbal numerical scale.

${ }^{\mathrm{g}}$ VAS: visual analog scale.

${ }^{\text {h}}$ CHEO: Children's Eastern Ontario Hospital Pain Scale.

${ }^{\mathrm{i}}$ MANOVA: multivariate analysis of variance.

${ }^{\mathrm{j}}$ NPS: numerical pain scale

${ }^{\mathrm{k}}$ CAS: color analog scale

${ }^{1}$ GRS: graphical representation scale.

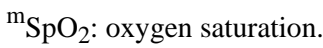

${ }^{\mathrm{n}}$ FAS: facial affective scale

\section{Effect on Anxiety}

Anxiety or stress was measured as a primary outcome in $44 \%$ of studies (8/18) [25,28,30-33,35,38]. Within these, 50\% (4/8) demonstrated a statistically significant reduction in anxiety;
$37.5 \%$ (3/8) demonstrated a statistically significant reduction in anxiety utilizing a between-group design [28,32,35]; and $12.5 \%(1 / 8)$ showed a statistically significant reduction in anxiety by means of a within-group design [25]. These results and the tools utilized to measure them are detailed in Table 3. 
Table 3. Summary measures of studies in review which measured forms of anxiety.

\begin{tabular}{|c|c|c|}
\hline Study & Measurement tools & Results \\
\hline Chad et al [25] & McMurtry children's fear scale & $\begin{array}{l}\text { Significant reduction in fear detected by parent due to } \mathrm{VR}^{\mathrm{a}} \text { (mean } 2.18 ; P=.05 \text { ). } \\
\text { Insignificant reduction in fear reported by child due to VR (mean } 2.57 ; P=.43 \text { ). }\end{array}$ \\
\hline Frey et al [28] & $\mathrm{VNS}^{\mathrm{b}}$ (scale of $\left.0-10\right)$ & $\begin{array}{l}\text { Anxiety was significantly decreased }-1.5(95 \% \mathrm{CI}-0.8 \text { to }-2.3) \text { in the VR condition compared } \\
\text { to that in the control condition. } \\
\text { Significant difference in anxiety found between VR group and non-VR group using ANOVA }{ }^{\mathrm{c}} \text {. }\end{array}$ \\
\hline Gershon et al [30] & $\begin{array}{l}\text { VAS }^{\mathrm{d}}(\text { scale of } 0-100) ; \mathrm{CHEO}^{\mathrm{e}} \\
\text { Pain Scale }\end{array}$ & $\begin{array}{l}\text { From the CHEO pain scale measure, the VR group had significantly fewer behavioral markers } \\
\text { in comparison to controls for anxiety }(P<.05) \text {. No summary measures were provided in paper. }\end{array}$ \\
\hline Glennon et al [31] & 5-point Likert scale for anxiety & $\begin{array}{l}\text { Participants in the VR group did not experience a statistically significant decrease in anxiety } \\
\text { in comparison to that in controls }(P>.05) \text {. }\end{array}$ \\
\hline Gold et al [32] & VAS (scale of 0-10); FAS ${ }^{f}$ & $\begin{array}{l}\text { Significantly less anxiety }(P<.05) \text { was reported and observed in the VR group (mean } 1.90, \mathrm{SD} \\
2.2 \text { ) compared to that in the control group (mean } 2.48, \text { SD } 2.07) \text {. }\end{array}$ \\
\hline McSherry et al [33] & VNS & $\begin{array}{l}\text { Anxiety scores were not significantly reduced }(P>.05) \text { in VR group (mean difference }-1.3 \text {, } \\
\text { SD 4.4) vs control (mean difference }-0.4, \mathrm{SD} 2.7) \text {. }\end{array}$ \\
\hline \multirow[t]{2}{*}{ Piskorz et al [35] } & VAS & $\begin{array}{l}\text { The VR group (mean } 11.16, \text { SD } 18.58) \text { reported significantly lower stress levels }(P<.01) \\
\text { compared to those in the control group (mean } 41.89, \text { SD } 40.89) \text {. }\end{array}$ \\
\hline & & $\begin{array}{l}\text { Stress levels were } 73.4 \% \text { lower in VR group against control with a large effect size (Cohen } \\
d=0.993 \text { ). }\end{array}$ \\
\hline Walker et al [38] & VAS & $\begin{array}{l}\text { No significant difference between intraprocedural anxiety levels. No descriptive statistics } \\
\text { were provided. }\end{array}$ \\
\hline
\end{tabular}

${ }^{\mathrm{a}} \mathrm{VR}$ : virtual reality.

${ }^{\mathrm{b}} \mathrm{VNS}$ : verbal numerical scale.

${ }^{\mathrm{c}}$ ANOVA: analysis of variance.

dVAS: visual analog scale.

eCHEO: Children's Eastern Ontario Hospital.

${ }^{f}$ FAS: facial affective scale.

\section{Effect on Physiological Parameters}

The effect of virtual reality on physiological indicators of pain was investigated in 39\% of studies (7/18) [17,19,30,34,37-39]; however, the parameters investigated varied between studies, encompassing measures such as heart rate, respiratory rate, oxygen saturation, galvanic skin response, blood pressure, and mean arterial pressure.

Of these, $29 \%$ of studies (2/7) demonstrated a significantly reduced heart rate in children or adolescents undergoing virtual reality therapy compared with that of the control group [30,39]. A summary of the results is presented in Table 4. 
Table 4. Summary of physiological measures and side effects of studies in this review.

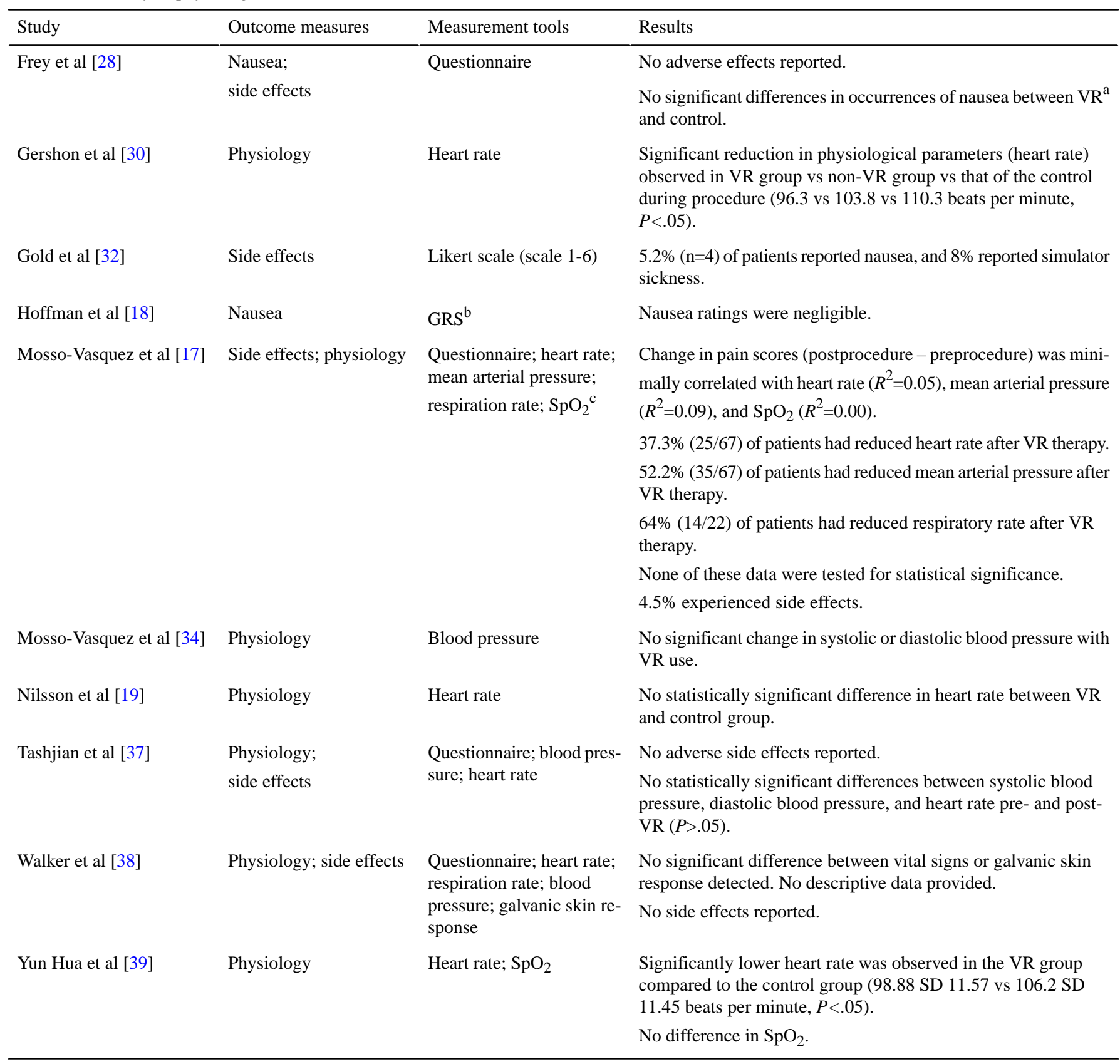

\footnotetext{
${ }^{\mathrm{a}} \mathrm{VR}$ : virtual reality.

${ }^{\mathrm{b}} \mathrm{GRS}$ : graphic rating scale.

${ }^{\mathrm{c}} \mathrm{SpO}_{2}$ : oxygen saturation.
}

\section{Side Effects}

Of the eligible studies, $33 \%(6 / 18)$ assessed patients for side effects incurred from virtual reality therapy $[17,18,28,32,37,38]$. The main side effects that were screened were include nausea, vomiting, and vertigo. Overall, the prevalence of side-effects was low and ranged from $0 \%$ to $8 \%$. This data is summarized in Table 4.

\section{Discussion}

\section{Effect on Analgesia}

The findings of this review illustrated that there was a significant reduction of pain related to virtual reality therapy utilization in $67 \%$ of the studies (12/18). Although acknowledging limitations in interpreting these findings (see limitations below), this evidence is corroborated by the findings of other high-quality studies [40-42], supporting the use of virtual reality therapy as a nonpharmacologic adjunct in facilitating analgesia within a clinical context. An effort was also made to critically appraise the studies which failed to demonstrate any significant differences in pain (Multimedia Appendix 3). The intention 
here was to examine the studies for factors which may have contributed toward null findings and were considered to be limitations of the study by the authors themselves.

To the practicing clinician, these findings are of relevance as they suggest that virtual reality therapy can be considered as an inpatient adjunct for acute pain, particularly in the context of facilitating procedural analgesia (12/18). However, it is likely that this performance will vary by indication and the patient population to which it is being applied. This variability in performance, therefore, should prompt consideration toward pilot testing, as an initial step, for any specific clinical use in order to establish its appropriateness as a therapeutic modality.

To further elaborate, although the exact mechanisms behind how virtual reality facilitates analgesia are still unknown; there are several plausible theories which may explain its therapeutic effect. One school of thought suggests that virtual reality therapy enacts changes on a neurobiological level, and thereby, facilitates analgesia in a manner similar to a drug. Functional magnetic resonance imaging has been utilized to demonstrate this in experimental models [43]. During episodes of pain stimulus, areas of the neuroanatomic pain matrix (insula, anterior cingulate cortex, thalamus, primary and secondary somatosensory cortices) demonstrated increased levels of activity. When virtual reality therapy is administered to patients during these episodes, a reduction greater than $50 \%$ is observed in the activity of the pain matrix, which corresponds with a fall in patient-reported pain ratings [43]. Similarly, experimental models have also demonstrated that this analgesic effect of virtual reality therapy can be controlled in a dose-dependent fashion [44-46].

Alternatively, it has also been theorized that virtual reality enacts its functions on a psychological level through the distraction it provides. The Gate Control Theory [16] proposes that the amount of attention given to a painful stimulus affects the person's interpretation of it. In line with this, the Multiple Resource Theory [15] also suggests that humans have a finite capacity to provide attention toward and process pain. As such, it is plausible that by rerouting or drawing these mental faculties away from the noxious stimulus, through a mechanism such as virtual reality therapy, that this would successfully attenuate the perception of pain $[42,47,48]$.

\section{Effect on Anxiety}

Within the brain, the limbic system and amygdala are implicated in mediating anxiety, and this is often experienced by patients prior to a medical procedure $[49,50]$. While the ability to be anxious is essential for survival, increased levels of anxiety in a clinical environment can lead to worsening perceptions of pain, decreased thresholds for pain, and less cooperative patients $[20,21]$. As such, a rationale does exist for controlling anxiety in the context of facilitating analgesia for patients.

The findings of the review with regard to anxiolysis were equivocal, with $50 \%(9 / 18)$ of the studies demonstrating a significant anxiolytic effect. A recent systematic review [51] demonstrated significantly reduced anxiety scores in individuals undergoing virtual reality therapy for treatment of anxiety disorders in comparison to those of controls. Similarly, there is also some suggestion that virtual reality therapy generates positive emotions and improvements in mood which dampen preprocedural patient anxiety. Also, it is supposed that similar to its analgesic effects, anxiolytic properties occur as a result of the abovementioned psychological alterations [52-54].

There appears to be merit in further evaluating virtual reality therapy for its anxiolytic effect. Particularly, as the potential benefits of anxiolysis extend beyond the mitigation of procedural pain to include an improved patient experience [55].

\section{Effect on Physiological Parameters}

Several studies have attempted to utilize changes in physiological markers or autonomic arousal as surrogate marker of analgesic effect [56]. From a biological perspective, this is not surprising since acute pain activates the sympathoadrenal fight or flight response, which in turn produces autonomic arousal effects (ie, increased respiratory rate, heart rate, blood pressure, skin sweating_galvanic skin response) [22,56-58].

In this review, 39\% of studies (7/18) explored the relationship between virtual reality therapy-facilitated analgesia and its effect on a variety of physiological parameters. Although our findings somewhat suggested that heart rate correlated with pain scores $[30,39]$, it was not possible to consistently ascribe utility toward using autonomic arousal as a surrogate marker for analgesic effect. There were several reasons for this.

First, parameters utilized and investigated across studies appeared to be heterogeneous and inconsistent, making it difficult to draw firm conclusions. Next, there was also evidence to suggest that not all physiological markers respond similarly to pain stimulus and subsequent analgesia [17,19,30,34,37-39]. Additionally, it is also known that arousal induced by pain is not static as the participant may be able to influence it either consciously or subconsciously by utilizing their own coping strategies (ie, heightened respiratory rate can be consciously altered by slowing down one's breathing) [56,58,59]. This, therefore, will arguably impact the ability of physiological markers to be precise and consistent markers of pain. However, it is worth mentioning that the literature seems to suggest that both respiratory rate and galvanic skin response appear to be consistent markers of pain response, whereas cardiovascular changes appear to be less useful $[56,58]$.

Considering these findings, it is safe to say that there is no firm evidence to suggest that virtual reality therapy can either affect autonomic arousal or demonstrate its analgesic properties through modulation of these parameters. Testing these parameters in a uniform and consistent manner, at least within a research context, is merited.

\section{Side Effects}

In this review, studies reported a low incidence $(0 \%-8 \%)$ of adverse effects in participants utilizing virtual reality therapy; however, it should be reiterated that only 6 studies screened for side effects.

Some of the main side-effects associated with virtual reality were nausea, vomiting, eye strain, and dizziness; cumulatively referred to as cybersickness [60]. The most widely accepted theory explaining cybersickness relates to the Sensory Conflict 
Theory. This refers to the discrepancy which occurs between the ocular and vestibular systems when the senses do not receive the usual sensory feedback that would be expected in such a scenario. This lack of synchronization is believed to cause cybersickness [61,62].

This is of relevance to the clinician using the technology for several reasons. For one, this alludes to a vulnerable population of patients who are susceptible to these side effects and who should be excluded from its use, such as patients with vestibular abnormalities, with seizure disorders, and who experience migraines or headaches [63]. Additionally, this alludes to a number of methods that can be considered to reduce the incidence of these effects during use of the technology. Although a discussion of these is beyond the scope of this review, the following articles provide adequate reference material [64-68].

\section{Virtual Reality Technological Perspectives}

Most virtual reality interactive hardware consists of a combination of a head mounted display, built-in biaural headphones for sound, and a trackpad or joystick for manipulation or navigation of the virtual environment, to provide the user with an immersive experience [69].

\section{Head Mounted Display and User Control}

In our review, all studies utilized a head mounted display for the administration of virtual reality to participants. These ranged from portable hardware, such as a helmet or piece of cardboard, to more sophisticated hardware systems, where participants were connected to an external processing unit.

A head mounted display displays content via 2 screens placed in front of the user's eyes which are stereoscopic in nature. The images displayed are angled to provide a variation in depth perception, which is interpreted by the brain as having $3 \mathrm{D}$ characteristics and features. In addition, the head mounted displays track user interaction in real time, which updates the virtual content that is reflected to the user simultaneously [70]. This can be either through tracking head orientation or position of the user's physical movements, as well as walking and jumping $[69,71]$. None of the studies in this review used systems capable of positional tracking. This is understandable, considering that clinical procedures, including those examined, typically necessitate controlled patient positioning.

\section{Virtual Reality Content}

In this study, $50 \%$ of the content was an active form of virtual reality, which entailed an element of interaction with the environment by the participant. In contrast, the remainder administered a passive form of virtual reality, where participants could only observe the content. This is worth mentioning as the available evidence suggests that the analgesia afforded by active virtual reality is significantly more than that offered by the passive form [72-74]. No study in our review, however, explicitly investigated this difference.

\section{Limitations}

The findings of this review should be interpreted considering the following limitations.
First, it is important to note that the results of this review could be influenced by publication bias. Particularly when considering that Fanelli et al [75] demonstrated that approximately $90 \%$ of literature in the fields of psychiatry, psychology, and clinical medicine report positive findings. As a result, the performance of virtual reality as an analgesic could be overestimated. Second, this limitation is further exacerbated by the use of a narrative approach employing descriptive statistics, as was the case for this review. Similarly, the search strategy was restricted to health databases given the interest in clinically relevant findings. However, in doing so, we neglected technical databases such as IEEE and ACM, which might have had further data of relevance. Unfortunately, this is an issue that plagues research in the field of medical technology as it attempts to incorporate the two very separate domains of health and technology. To bridge this, we have provided information in the discussion to supplement areas where more technical knowledge may have been required. Third, as the sample sizes of the studies included in this review were generally small and based on very specific inpatient populations, the generalizability of the findings may be limited. In addition to this, a large variety of measurement tools were implemented to quantify the outcome of pain. This unfortunately precludes meta-analysis of the data, which would have otherwise been useful to quantify accurate treatment effects.

\section{Areas for Future Research}

The systematic review highlighted the need for further large-scale prospective studies to be conducted in order to investigate the efficacy of virtual reality therapy in facilitating analgesia and anxiolysis. Additionally, this review also highlighted the need for investigators to screen patients for cybersickness-related side effects as part of their study design. Finally, it is also suggested that future clinical studies explore the differences between active and passive forms of virtual reality in facilitating analgesia.

\section{Conclusion}

This review sheds light on the efficacy of utilizing virtual reality therapy for the reduction of acute pain and procedural anxiety within an inpatient setting to hopefully offer a novel and practical perspective on the matter. Furthermore, it demonstrated a low incidence of adverse side effects in the populations being sampled. For clinical use, there appeared to be a preference for head mounted display to display virtual reality content. Although no differences between active and passive virtual reality were identified in this review, the literature appeared to suggest that active virtual reality would facilitate a higher level of analgesia in comparison to that facilitated by passive virtual reality [72-74]. Finally, although there was no evidence found to suggest an effect of virtual reality therapy on physiological parameters (autonomic arousal) as a surrogate biomarker of pain, this review also suggested merit in continuing this line of investigation in a rigorous and reproducible manner. It is hoped that this study serves to inform future trials to assess the efficacy of virtual reality in the treatment of acute pain. 


\section{Authors' Contributions}

VS and RRW contributed equally to this paper. VS, FDSC, EMW, and BV conceived and designed the search. VS, RRW, JS, OP, AN, and SK analyzed the data. VS, RRW, JS, OP, and SK wrote the paper. VS, RRW, JS, OP, SK, FDSC, EMW, and BV interpreted the data and critically revised the manuscript. All authors reviewed and approved the manuscript.

\section{Conflicts of Interest}

None declared.

\section{Multimedia Appendix 1}

General description of studies included in the review.

[DOCX File, 34 KB-Multimedia Appendix 1]

\section{Multimedia Appendix 2}

Technical specification of devices.

[DOCX File, 31 KB-Multimedia Appendix 2]

\section{Multimedia Appendix 3}

Critical appraisal of studies which failed to demonstrate a significant reduction in pain scores.

[DOCX File, 16 KB-Multimedia Appendix 3]

\section{References}

1. Merskey H, Bogduk N. Classification of Chronic Pain 2nd ed. Seattle: IASP Press; 1994. URL: https://s3.amazonaws.com/ $\underline{\text { rdcms-iasp/files/production/public/Content/ContentFolders/Publications2/FreeBooks/Classification-of-Chronic-Pain.pdf }}$ [accessed 2020-10-23]

2. Federation of State Medical Boards of the United States, Inc. Model policy for the use of controlled substances for the treatment of pain. J Pain Palliat Care Pharmacother 2005;19(2):73-78. [Medline: 16061467]

3. Noble M, Treadwell J, Tregear S, Coates VH, Wiffen PJ, Akafomo C, et al. Long-term opioid management for chronic noncancer pain. Cochrane Database Syst Rev 2010 Jan 20(1):CD006605 [FREE Full text] [doi:

10.1002/14651858.CD006605.pub2] [Medline: 20091598]

4. Rosenblum A, Marsch LA, Joseph H, Portenoy RK. Opioids and the treatment of chronic pain: controversies, current status, and future directions. Exp Clin Psychopharmacol 2008 Oct;16(5):405-416 [FREE Full text] [doi: 10.1037/a0013628] [Medline: 18837637$]$

5. Gandhi K, Heitz JW, Viscusi ER. Challenges in acute pain management. Anesthesiol Clin 2011 Jun;29(2):291-309. [doi: 10.1016/j.anclin.2011.04.009] [Medline: 21620344]

6. Wardhan R, Chelly J. Recent advances in acute pain management: understanding the mechanisms of acute pain, the prescription of opioids, and the role of multimodal pain therapy. F1000Res 2017;6:2065 [FREE Full text] [doi: 10.12688/f1000research.12286.1] [Medline: 29225793]

7. Stewart WF, Ricci J, Chee E, Morganstein D, Lipton R. Lost productive time and cost due to common pain conditions in the US workforce. JAMA 2003 Nov 12;290(18):2443-2454. [doi: 10.1001/jama.290.18.2443] [Medline: 14612481]

8. Gregory J, McGowan L. An examination of the prevalence of acute pain for hospitalised adult patients: a systematic review. J Clin Nurs 2016 Mar;25(5-6):583-598. [doi: 10.1111/jocn.13094] [Medline: 26778249]

9. Won A, Bailey J, Bailenson J, Tataru C, Yoon I, Golianu B. Immersive virtual reality for pediatric pain. Children (Basel) 2017 Jun 23;4(7):52 [FREE Full text] [doi: 10.3390/children4070052] [Medline: 28644422]

10. Blondell R, Azadfard M, Wisniewski A. Pharmacologic therapy for acute pain. Am Fam Physician 2013 Jun 01;87(11):766-772 [FREE Full text] [Medline: 23939498]

11. Wiederhold BK, Soomro A, Riva G, Wiederhold MD. Future directions: advances and implications of virtual environments designed for pain management. Cyberpsychol Behav Soc Netw 2014 Jun;17(6):414-422 [FREE Full text] [doi: 10.1089/cyber.2014.0197] [Medline: 24892206]

12. Chou R, Gordon DB, de Leon-Casasola OA, Rosenberg JM, Bickler S, Brennan T, et al. Management of postoperative pain: a clinical practice guideline from the American Pain Society, the American Society of Regional Anesthesia and Pain Medicine, and the American Society of Anesthesiologists' Committee on Regional Anesthesia, Executive Committee, and Administrative Council. J Pain 2016 Feb;17(2):131-157. [doi: 10.1016/j.jpain.2015.12.008] [Medline: 26827847]

13. Trost Z, Zielke M, Guck A, Nowlin L, Zakhidov D, France CR, et al. The promise and challenge of virtual gaming technologies for chronic pain: the case of graded exposure for low back pain. Pain Manag 2015;5(3):197-206. [doi: 10.2217/pmt.15.6] [Medline: 25971643] 
14. Hoffman HG, Doctor JN, Patterson DR, Carrougher GJ, Furness TA. Virtual reality as an adjunctive pain control during burn wound care in adolescent patients. Pain 2000 Mar;85(1-2):305-309. [doi: 10.1016/s0304-3959(99)00275-4] [Medline: 10692634]

15. Wickens C. Processing Resources in Attention, Dual Task Performance, and Workload Assessment. USA: Defense Technical Information Center; 1981. URL: https://apps.dtic.mil/dtic/tr/fulltext/u2/a102719.pdf [accessed 2020-10-23]

16. Melzack R, Wall PD. Pain mechanisms: a new theory. Science 1965 Nov 19;150(3699):971-979. [doi: 10.1126/science.150.3699.971] [Medline: 5320816]

17. Mosso-Vázquez JL, Gao K, Wiederhold BK, Wiederhold MD. Virtual reality for pain management in cardiac surgery. Cyberpsychol Behav Soc Netw 2014 Jun;17(6):371-378 [FREE Full text] [doi: 10.1089/cyber.2014.0198] [Medline: 24892200]

18. Hoffman HG, Patterson DR, Seibel E, Soltani M, Jewett-Leahy L, Sharar SR. Virtual reality pain control during burn wound debridement in the hydrotank. Clin J Pain 2008 May;24(4):299-304. [doi: 10.1097/AJP.0b013e318164d2cc] [Medline: 18427228]

19. Nilsson S, Finnström B, Kokinsky E, Enskär K. The use of virtual reality for needle-related procedural pain and distress in children and adolescents in a paediatric oncology unit. Eur J Oncol Nurs 2009 Apr;13(2):102-109. [doi: 10.1016/j.ejon.2009.01.003] [Medline: 19230769]

20. Andrasik F, Flor H, Turk DC. An expanded view of psychological aspects in head pain: the biopsychosocial model. Neurol Sci 2005 May;26 Suppl 2:s87-s91. [doi: 10.1007/s10072-005-0416-7] [Medline: 15926029]

21. Mosso J, Gorini A, De La Cerda G, Obrador T, Almazan A, Mosso D, et al. Virtual reality on mobile phones to reduce anxiety in outpatient surgery. Stud Health Technol Inform 2009;142:195-200. [Medline: 19377147]

22. Cowen R, Stasiowska MK, Laycock H, Bantel C. Assessing pain objectively: the use of physiological markers. Anaesthesia $2015 \mathrm{Jul}$;0(7):828-847 [FREE Full text] [doi: 10.1111/anae.13018] [Medline: 25772783]

23. Price D, Graham C, Parkin CG, Peyser TA. Are systematic reviews and meta-analyses appropriate tools for assessing evolving medical device technologies? J Diabetes Sci Technol 2015 Sep 29;10(2):439-446 [FREE Full text] [doi: 10.1177/1932296815607863] [Medline: 26420626]

24. Downs SH, Black N. The feasibility of creating a checklist for the assessment of the methodological quality both of randomised and non-randomised studies of health care interventions. J Epidemiol Community Health 1998 Jun;52(6):377-384. [doi: 10.1136/jech.52.6.377] [Medline: 9764259]

25. Chad R, Emaan S, Jillian O. Effect of virtual reality headset for pediatric fear and pain distraction during immunization. Pain Manag 2018 May;8(3):175-179. [doi: 10.2217/pmt-2017-0040] [Medline: 29722606]

26. Chan EA, Chung JW, Wong TK, Lien AS, Yang JY. Application of a virtual reality prototype for pain relief of pediatric burn in Taiwan. J Clin Nurs 2007 Apr;16(4):786-793. [doi: 10.1111/j.1365-2702.2006.01719.x] [Medline: 17402961]

27. Chau B, Chi B, Wilson T. Decreasing pediatric pain and agitation during botulinum toxin injections for spasticity with virtual reality: Lessons learned from clinical use. J Pediatr Rehabil Med 2018;11(3):199-204. [doi: 10.3233/PRM-180534] [Medline: $\underline{\text { 30223406] }}$

28. Frey DP, Bauer ME, Bell CL, Low LK, Hassett AL, Cassidy RB, et al. Virtual reality analgesia in labor: the VRAIL pilot study-a preliminary randomized controlled trial suggesting benefit of immersive virtual reality analgesia in unmedicated laboring women. Anesth Analg 2019 Jun;128(6):e93-e96. [doi: 10.1213/ANE.0000000000003649] [Medline: $\underline{31094789]}$

29. Gerçeker GÖ, Binay ?, Bilsin E, Kahraman A, Yılmaz HB. Effects of virtual reality and external cold and vibration on pain in 7- to 12-year-old children during phlebotomy: a randomized controlled trial. J Perianesth Nurs 2018 Dec;33(6):981-989. [doi: 10.1016/j.jopan.2017.12.010] [Medline: 29559294]

30. Gershon J, Zimand E, Pickering M, Rothbaum BO, Hodges L. A pilot and feasibility study of virtual reality as a distraction for children with cancer. J Am Acad Child Adolesc Psychiatry 2004 Oct;43(10):1243-1249. [doi: 10.1097/01.chi.0000135621.23145.05] [Medline: 15381891$]$

31. Glennon C, McElroy S, Connelly L, Mische Lawson L, Bretches A, Gard A, et al. Use of virtual reality to distract from pain and anxiety. Oncol Nurs Forum 2018 Jul 02;45(4):545-552. [doi: 10.1188/18.ONF.545-552] [Medline: 29947355]

32. Gold J, Mahrer N. Is virtual reality ready for prime time in the medical space? a randomized control trial of pediatric virtual reality for acute procedural pain management. J Pediatr Psychol 2018 Apr 01;43(3):266-275. [doi: 10.1093/jpepsy/jsx129] [Medline: 29053848]

33. McSherry T, Atterbury M, Gartner S, Helmold E, Searles DM, Schulman C. Randomized, crossover study of immersive virtual reality to decrease opioid use during painful wound care procedures in adults. J Burn Care Res 2018 Feb 20;39(2):278-285. [doi: 10.1097/BCR.0000000000000589] [Medline: 28570305]

34. Mosso Vázquez JL, Mosso Lara D, Mosso Lara JL, Miller I, Wiederhold MD, Wiederhold BK. Pain distraction during ambulatory surgery: virtual reality and mobile devices. Cyberpsychol Behav Soc Netw 2019 Jan;22(1):15-21. [doi: 10.1089/cyber.2017.0714] [Medline: 30256662]

35. Piskorz J, Czub M. Effectiveness of a virtual reality intervention to minimize pediatric stress and pain intensity during venipuncture. J Spec Pediatr Nurs 2018 Jan;23(1):1. [doi: 10.1111/jspn.12201] [Medline: 29155488] 
36. JahaniShoorab N, Ebrahimzadeh Zagami S, Nahvi A, Mazluom SR, Golmakani N, Talebi M, et al. The effect of virtual reality on pain in primiparity women during episiotomy repair: a randomize clinical trial. Iran J Med Sci 2015 May;40(3):219-224 [FREE Full text] [Medline: 25999621]

37. Tashjian VC, Mosadeghi S, Howard AR, Lopez M, Dupuy T, Reid M, et al. Virtual reality for management of pain in hospitalized patients: results of a controlled trial. JMIR Ment Health 2017 Mar 29;4(1):e9 [FREE Full text] [doi: 10.2196/mental.7387] [Medline: 28356241]

38. Walker MR, Kallingal GJ, Musser JE, Folen R, Stetz MC, Clark JY. Treatment efficacy of virtual reality distraction in the reduction of pain and anxiety during cystoscopy. Mil Med 2014 Aug;179(8):891-896. [doi: 10.7205/MILMED-D-13-00343] [Medline: 25102532]

39. Hua Y, Qiu R, Yao W, Zhang Q, Chen X. The effect of virtual reality distraction on pain relief during dressing changes in children with chronic wounds on lower limbs. Pain Manag Nurs 2015 Oct;16(5):685-691. [doi: 10.1016/j.pmn.2015.03.001] [Medline: 25972074]

40. Li A, Montaño Z, Chen VJ, Gold JI. Virtual reality and pain management: current trends and future directions. Pain Manag 2011 Mar;1(2):147-157 [FREE Full text] [doi: 10.2217/pmt.10.15] [Medline: 21779307]

41. Dascal J, Reid M, IsHak W, Spiegel B, Recacho J, Rosen B, et al. Virtual reality and medical inpatients: a systematic review of randomized, controlled trials. Innov Clin Neurosci 2017;14(1-2):14-21 [FREE Full text] [Medline: 28386517]

42. Gupta A, Scott K, Dukewich M. Innovative technology using virtual reality in the treatment of pain: does it reduce pain via distraction, or is there more to it? Pain Med 2018 Jan 01;19(1):151-159. [doi: 10.1093/pm/pnx109] [Medline: 29025113]

43. Hoffman HG, Richards TL, Bills AR, Van Oostrom T, Magula J, Seibel EJ, et al. Using FMRI to study the neural correlates of virtual reality analgesia. CNS Spectr 2006 Jan;11(1):45-51. [doi: 10.1017/s1092852900024202] [Medline: 16400255]

44. Loreto-Quijada D, Gutiérrez-Maldonado J, Nieto R, Gutiérrez-Martínez O, Ferrer-García M, Saldaña C, et al. Differential effects of two virtual reality interventions: distraction versus pain control. Cyberpsychol Behav Soc Netw 2014 Jun;17(6):353-358. [doi: 10.1089/cyber.2014.0057] [Medline: 24892197]

45. Mahrer NE, Gold JI. The use of virtual reality for pain control: a review. Curr Pain Headache Rep 2009 Apr;13(2):100-109. [doi: 10.1007/s11916-009-0019-8] [Medline: 19272275]

46. Hoffman HG, Sharar SR, Coda B, Everett JJ, Ciol M, Richards T, et al. Manipulating presence influences the magnitude of virtual reality analgesia. Pain 2004 Sep;111(1-2):162-168. [doi: 10.1016/j.pain.2004.06.013] [Medline: 15327820]

47. Hoffman HG, Garcia-Palacios A, Kapa V, Beecher J, Sharar SR. Immersive virtual reality for reducing experimental ischemic pain. International Journal of Human-Computer Interaction 2003 Jun;15(3):469-486. [doi:

10.1207/S15327590IJHC1503 10]

48. McCaul KD, Malott JM. Distraction and coping with pain. Psychological Bulletin 1984;95(3):516-533. [doi: 10.1037/0033-2909.95.3.516]

49. Silverthorn D, Johnson B, Ober W, Ober C, Silverthorn A. Human Physiology: An Integrated Approach. London, UK: Pearson; 2016:2016.

50. Rosen JB, Schulkin J. From normal fear to pathological anxiety. Psychol Rev 1998 Apr;105(2):325-350. [doi: 10.1037/0033-295x.105.2.325] [Medline: 9577241]

51. Fodor LA, Cote CD, Cuijpers P, Szamoskozi S, David D, Cristea IA. The effectiveness of virtual reality based interventions for symptoms of anxiety and depression: a meta-analysis. Sci Rep 2018 Jul 09;8(1):10323 [FREE Full text] [doi: 10.1038/s41598-018-28113-6] [Medline: 29985400]

52. Triberti S, Repetto C, Riva G. Psychological factors influencing the effectiveness of virtual reality-based analgesia: a systematic review. Cyberpsychol Behav Soc Netw 2014 Jun;17(6):335-345. [doi: 10.1089/cyber.2014.0054] [Medline: 24892195]

53. Ganry L, Hersant B, Sidahmed-Mezi M, Dhonneur G, Meningaud J. Using virtual reality to control preoperative anxiety in ambulatory surgery patients: a pilot study in maxillofacial and plastic surgery. J Stomatol Oral Maxillofac Surg 2018 Sep;119(4):257-261. [doi: 10.1016/j.jormas.2017.12.010] [Medline: 29317347]

54. Koepp MJ, Gunn RN, Lawrence AD, Cunningham VJ, Dagher A, Jones T, et al. Evidence for striatal dopamine release during a video game. Nature 1998 May 21;393(6682):266-268. [doi: 10.1038/30498] [Medline: $\underline{9607763}$ ]

55. Smith V, Warty RR, Kashyap R, Neil P, Adriaans C, Nair A, et al. A randomised controlled trial to assess the feasibility of utilising virtual reality to facilitate analgesia during external cephalic version. Sci Rep 2020 Feb 21;10(1):3141 [FREE Full text] [doi: 10.1038/s41598-020-60040-3] [Medline: $\underline{\text { 32081989] }}$

56. Kyle BN, McNeil DW. Autonomic arousal and experimentally induced pain: a critical review of the literature. Pain Res Manag 2014;19(3):159-167 [FREE Full text] [doi: 10.1155/2014/536859] [Medline: 24533429]

57. Terkelsen AJ, Andersen OK, Molgaard H, Hansen J, Jensen TS. Mental stress inhibits pain perception and heart rate variability but not a nociceptive withdrawal reflex. Acta Physiol Scand 2004 Apr;180(4):405-414. [doi: 10.1111/j.1365-201x.2004.01263.x]

58. Kyle BN, McNeil DW. Autonomic arousal and experimentally induced pain: a critical review of the literature. Pain Res Manag 2014;19(3):159-167 [FREE Full text] [doi: 10.1155/2014/536859] [Medline: 24533429] 
59. Hohenschurz-Schmidt DJ, Calcagnini G, Dipasquale O, Jackson JB, Medina S, O'Daly O, et al. Linking pain sensation to the autonomic nervous system: the role of the anterior cingulate and periaqueductal gray resting-state networks. Front Neurosci 2020;14:147 [FREE Full text] [doi: 10.3389/fnins.2020.00147] [Medline: 33041747]

60. Almeida A, Rebelo F, Noriega P, Vilar E. Virtual reality self induced cybersickness: an exploratory study. In: Rebelo F, Soares M, editors. Advances in Ergonomics in Design. Advances in Intelligent Systems and Computing, vol 588. Cham, Switzerland: Springer Internatinal; 2018:A.

61. LaViola JJ. A discussion of cybersickness in virtual environments. SIGCHI Bull 2000 Jan 01;32(1):47-56. [doi: $10.1145 / 333329.333344]$

62. Shafer D, Carbonara C, Korpi M. Modern virtual reality technology: cybersickness, sense of presence, and gender. Media Psychology Review 2017;11(2):1 [FREE Full text]

63. Gorini A, Riva G. Virtual reality in anxiety disorders: the past and the future. Expert Rev Neurother 2008 Feb;8(2):215-233. [doi: 10.1586/14737175.8.2.215] [Medline: 18271709]

64. Pausch R, Crea T, Conway M. A Literature Survey for Virtual Environments: Military Flight Simulator Visual Systems and Simulator Sickness. 1992 Jan;1(3):344-363. [doi: 10.1162/pres.1992.1.3.344]

65. Mourant RR, Thattacherry TR. Simulator sickness in a virtual environments driving simulator. Proceedings of the Human Factors and Ergonomics Society Annual Meeting 2016 Nov 06;44(5):534-537. [doi: 10.1177/154193120004400513]

66. Lo W, So RH. Cybersickness in the presence of scene rotational movements along different axes. Applied Ergonomics 2001 Feb;32(1):1-14. [doi: 10.1016/s0003-6870(00)00059-4]

67. McCauley ME, Sharkey TJ. Cybersickness: perception of self-motion in virtual environments. 1992 Jan;1(3):311-318. [doi: 10.1162/pres.1992.1.3.311]

68. Rebenitsch L. Managing cybersickness in virtual reality. XRDS 2015 Sep 06;22(1):46-51. [doi: 10.1145/2810054]

69. Lee J, Ahn SC, Hwang J. A walking-in-place method for virtual reality using position and orientation tracking. Sensors (Basel) 2018 Aug 27;18(9):2832 [FREE Full text] [doi: 10.3390/s18092832] [Medline: 30150586]

70. de Franca A, Soares M. Review of virtual reality technology: an ergonomic approach and current challenges. In: de Franca A, Soares M, editors. Advances in Ergonomics in Design. AHFE 2017. Advances in Intelligent Systems and Computing, vol 588. Cham, Switzerland: Springer International; 2018:52-61.

71. Sherman W, Sherman WR, Craig A. Understanding Virtual Reality Interface, Application, and Design. San Francisco, CA: Elsevier Science; 2003.

72. Gutierrez-Martinez O, Gutierrez-Maldonado J, Cabas-Hoyos K, Loreto D. The illusion of presence influences VR distraction: effects on cold-pressor pain. Stud Health Technol Inform 2010;154:155-159. [Medline: 20543289]

73. Gutiérrez-Martínez O, Gutiérrez-Maldonado J, Loreto-Quijada D. Control over the virtual environment influences the presence and efficacy of a virtual reality intervention on pain. Stud Health Technol Inform 2011;167:111-115. [Medline: 21685651]

74. Gutierrez-Maldonado J, Gutierrez-Martinez O, Cabas-Hoyos K. Interactive and passive virtual reality distraction: effects on presence and pain intensity. Stud Health Technol Inform 2011;167:69-73. [Medline: 21685644]

75. Fanelli D. "Positive" results increase down the Hierarchy of the Sciences. PLoS One 2010 Apr 07;5(4):e10068 [FREE Full text] [doi: 10.1371/journal.pone.0010068] [Medline: 20383332]

Edited by G Eysenbach; submitted 26.01.20; peer-reviewed by D Gromala, I Danovitch, R Montgomery; comments to author 30.03.20;
revised version received 27.07.20; accepted 02.10.20; published 02.11.20
Please cite as:
Smith V, Warty RR, Sursas JA, Payne O, Nair A, Krishnan S, da Silva Costa F, Wallace EM, Vollenhoven B
The Effectiveness of Virtual Reality in Managing Acute Pain and Anxiety for Medical Inpatients: Systematic Review
J Med Internet Res 2020;22(11):e17980
URL: $\underline{\text { https://www.jmir.org/2020/11/e17980 }}$
doi: $\underline{10.2196 / 17980}$
PMID: $\underline{3136055}$

(CVinayak Smith, Ritesh Rikain Warty, Joel Arun Sursas, Olivia Payne, Amrish Nair, Sathya Krishnan, Fabricio da Silva Costa, Euan Morrison Wallace, Beverley Vollenhoven. Originally published in the Journal of Medical Internet Research (http://www.jmir.org), 02.11.2020. This is an open-access article distributed under the terms of the Creative Commons Attribution License (https://creativecommons.org/licenses/by/4.0/), which permits unrestricted use, distribution, and reproduction in any medium, provided the original work, first published in the Journal of Medical Internet Research, is properly cited. The complete bibliographic information, a link to the original publication on http://www.jmir.org/, as well as this copyright and license information must be included. 